\title{
Percieved Importance and Perfomance of Information Systems in Azam Company- Dar Es Salaam
}

\author{
Silvance O. Abeka (Corresponding author) \\ Dept. of Computer Studies, Kampala International University- Dar es salaam College \\ PO Box 9790, Dar es salaam, Tanzania \\ Tel: +2559928080Ｅ-mail: silvancea@yahoo.com
}

Evance Ochieng' Abeka

Dept. of Economics \& Business studies

Maseno University, Private bag, Maseno

Tel: +255 $736245421 \quad$ E-mail: abeka.evance@gmail.com

Accepted: March 27, 2012 Published: May 2, 2012

Doi:10.5296/ijld.v2i3.1755 URL: http://dx.doi.org/10.5296/ijld.v2i3.1755

\begin{abstract}
It is increasingly more interesting to the Companies to understand the relationship existing between perceived importance and performance of information systems within their companies.

The purpose of this paper is to explore the perception of the importance of attributes of information systems and whether the performance of information systems met the users' expectations in Azam company in Dar es salaam. Anonymous and self-administered questionnaires were distributed to 217 respondents. A total of 185 usable responses were received, resulting in a response rate of $85.3 \%$ which was considered satisfactory for subsequent analysis. Using an end-user satisfaction survey, It was discovered that the end-users were moderately satisfied with the company's IS performance and that there were gaps between importance and performance on all the systems-related attributes studied. The largest gap pertained to the attributes Understanding Systems and Documentation. The contribution of the study is in advancing Importance-Performance Analysis applicable to IS research.
\end{abstract}

Keywords: Information Systems Performance, Information Systems Importance, End-user Satisfaction 


\section{INTRODUCTION}

There is widespread research interest in information and communication technologies (ICTs). According to Crede and Mansell (1998), ICTs are crucially important for sustainable development in developing countries. Thioune (2003) notes that for the past two decades most developed countries have witnessed significant changes that can be traced to ICTs. These multi-dimensional changes have been observed in almost all aspects of life: economics, education, communication, and travel. In a technology driven society, getting information quickly is important for both sender and receiver. ICTs have made it possible to quickly find and distribute information. Thoiune (2003) indicates that many initiatives have taken at the international level to support Africa's efforts to develop a communication infrastructure and these efforts are designed to enable African countries, including Tanzania, to find faster ways to achieve durable and sustainable development.

User satisfaction is generally regarded as one of the most important measures of Information Systems success. There has been considerable research devoted to establishing a standard user satisfaction instrument since the 1980s (Ives et al. 1983; Bailey and Pearson 1983; Baroudi et al. 1986; Benson 1983), when data computing in organizations moved from data processing to end-user computing (EUC) (Doll and Torkzadeh 1988). Doll and Torkzadeh (1988) developed and validated an End-User Computing Satisfaction (EUCS) instrument. It included five components: content, accuracy, format, ease of use, and timeliness.

In the past, end-users interacted with systems via the system analyst or programmer who translated the user requirements into system input in order to generate the output required for the end-users' analysis and decision making process. However, now end-users are more directly involved with the systems as they navigate themselves typically via an interactive user interface, thus assuming more responsibility for their own applications. Therefore, the ability to capture and measure end-user satisfaction serves as a tangible surrogate measure in determining the performance of the IS function and services, and of IS themselves (Ives, Olson, \& Baroudi, 1983). Besides evaluating IS performance, it is also important to evaluate whether IS in an organization meet users' expectations. This paper aims to demonstrate the use of Importance- Performance Analysis (IPA) in evaluating IS.

\section{LITERATURE REVIEW}

\section{Importance- Performance Analysis (IPA)}

Importance-Performance Analysis, IPA, was formulated by Martilla and James (1977). It was dubbed action grid analysis, AGA, by Blake, Shrader, and James (1978). It is not just an analysis methodology. It is implicitly a theory of behavior. It was introduced as a way of understanding clients' needs and desires so as to make good management decisions about how to respond to them. By finding out about what people think about importance and performance on manipulatable attributes of a product, it is reasonable to think that one can come to some 
reasonable conclusions about modifying performance on attributes to e.g. increase profit or client satisfaction effectively.

Importance- Performance Analysis (IPA) conceptually underlies the multi-attribute models that date back to the late 1970s. Martilla and James (1977) applied the IPA technique to analyse the performance of the automobile industry. Hawes, Kiser and Rao (1982) and Hawes and Rao (1985) used the IPA concept in retirement communities and health care applications. Sethna (1982) found the IPA technique to be a valid and powerful technique for identifying service quality areas that require remedial strategic actions. The underlying assumption of the IPA technique is that customers' level of satisfaction with the attributes is mainly derived from their expectations and judgment of the product's or service's performance. IPA has become a popular managerial tool that has been broadly used to identify the strengths and weaknesses of brands, products, services and retail establishments in various industries in recent years (Chapman, 1993; Cheron, McTavish \& Perrien, 1989). Hemmasi, Strong and Taylor (1994) measured the service quality of hospital services using IPA as an alternative to the traditional SERVQUAL instrument devised by Parasuraman, Zeithaml and Berry (1988). While Evans and Chon (1989) used the IPA to formulate and evaluate tourism policy, Keyt, Yavas and Riecken (1994) and Hsu, Byun and Yang (1997) adopted the IPA technique in restaurant positioning. Lewis (1985) used the IPA as a competitive analysis technique to identify tourists' perceptions of the hotel industry. Lewis and Chambers (1989) reported the effective use of IPA by the Sheraton Hotel in monitoring customer satisfaction. Almanza, Jaffe and Lin (1994) used the IPA matrix to determine means for improving customer satisfaction. Martin (1995) examined service providers' perceptions of customers' expectations of quality service in the hotel industry using the IPA technique. In an increasingly competitive environment, a determination of the strengths and weaknesses of a product's or service's importance and performance seems an undeniable constituent of success.

Slack (1994) used it to study operations strategy while Sampson and Showalter (1999) evaluated customers. Ford, Joseph, and Joseph (1999) used IPA in the area of marketing strategy. IPA is also used in various industries, such as health (Dolinsky \& Caputo, 1991; Skok, Kophamel, \& Richardson, 2001), banking (Joseph, Allbrigth, Stone, Sekhon, \& Tinson 2005; Yeo, 2003), hotel (Weber, 2000), and tourism (Duke \& Mont 1996). In Tanzania, research by Wade and Eagles (2003), on IPA and Market Segmentation for Tourism Management in Parks and Protected Areas in Tanzania found out that Importance-performance analysis coupled with market segmentation is a useful exercise for protected area managers to measure service quality. The technique is achievable for agencies lacking expertise and resources such as Tanzania National Parks (TANAPA), and provides a simple and visual aid for the diagnosis of tourism service quality in protected areas. The IPA has also been applied in IS research. Magal and Levenburg (2005) employed IPA to study the motivations behind e-business strategies among small businesses while Shaw, Delone, and Niederman (2002) used it to analyze end-user support. Skok and colleagues (2001) mapped out the IPA using the Delone and McLean IS success model. In Kenya, the result of the importance- performance analysis conducted by Ombati, Maguta, Nyamwange and Nyaoga 
(2010) indicates that there is a perceptual problem when the sample indicated poor performance of electronic banking facilities compared with an ideal banking service. Therefore they proposed that the banks' management should also improve their ATM systems so as to minimize waiting time in the queue. This will improve the efficiency in the service delivery hence boosts customer confidence.

Delone and McLean (1992) used the construct of end-user satisfaction as a proxy measure of systems performance. Firstly, End-User Satisfaction has a high face validity since it is hard to deny that an information system is successful when it is favored by the users. Secondly, the development of the Bailey and Pearson instrument (1983) and its derivatives provided a reliable tool for measuring user satisfaction, which also facilitates comparison among studies. Thirdly, the measurement of end-user satisfaction is relatively more popular since other measures have performed poorly.

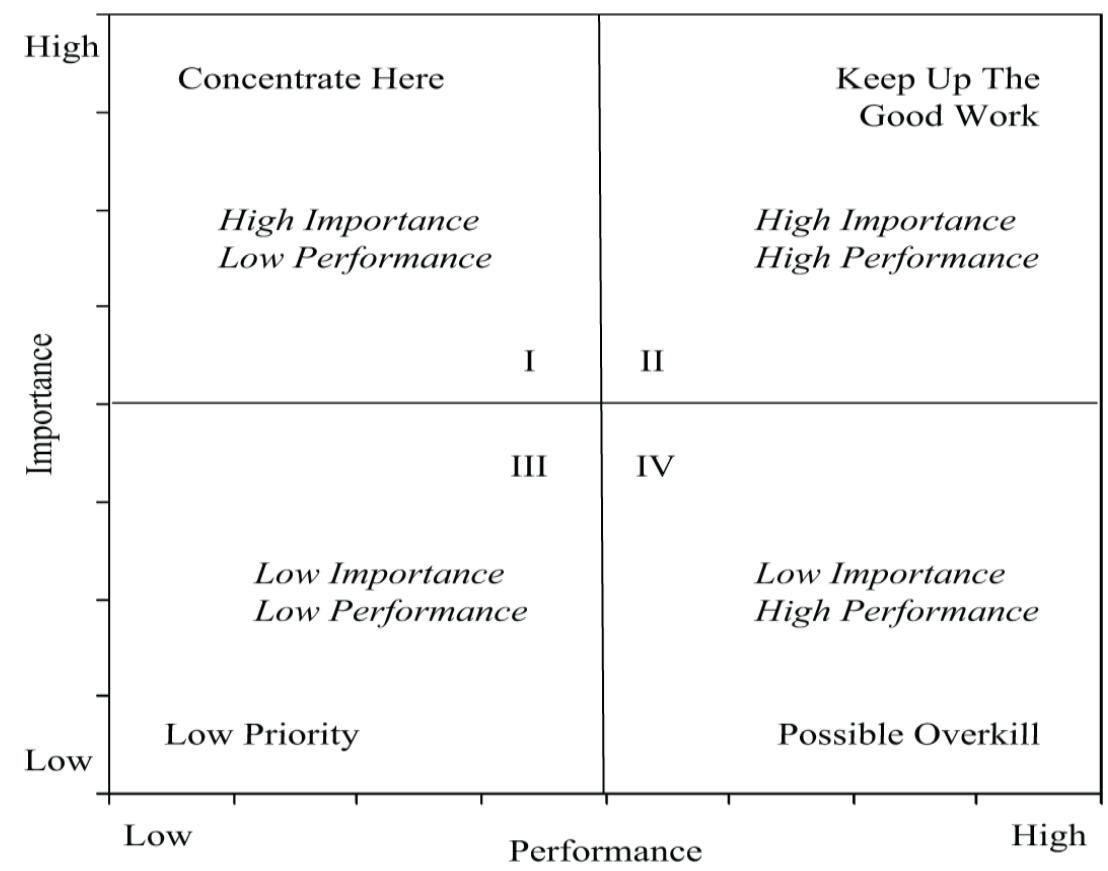

Source: Martilla \& James (1977)

Fig. 1. Importance- Performance Analysis grid.

The interpretation of the IPA is graphically presented on a grid divided into four quadrants. Fig. 1 above illustrates the IPA grid. The Y-axis reports the customers' perceived importance of selected attributes, and the X-axis shows the product's (or service's) performance in relation to these attributes. The four identifiable quadrants are; Concentrate Here, Keep Up the Good Work, Low Priority and Possible Overkill.

Quadrant I 
Attributes are perceived to be very important to respondents, but performance levels are fairly low. This sends a direct message that improvement efforts should concentrate here.

Quadrant II

Attributes are perceived to be very important to respondents, and at the same time, the organization seems to have high levels of performance on these activities. The message here is To Keep up the Good Work.

Quadrant III

Attributes are with low importance and low performance. Although performance levels may be low in this cell, managers should not be overly concerned since the attribute in this cell is not perceived to be very important. Limited resources should be expended on this low priority cell.

Quadrant IV

This cell contains attributes of low importance, but relatively high performance. Respondents are satisfied with the performance of the organizations, but managers should consider present efforts on the attributes of this cell as being over-utilised.

Sources: Adapted from (Evans and Chon, 1989; Hemmasi, Strong \& Taylor, 1994; Keyt et al., 1994; Martilla \& James, 1977; Martin, 1995).

\section{METHODOLOGY}

\section{Research Population and Sample}

The researcher targeted population were the organization's end-users of various IS (network access, email, Internet browsing, and a host of office automation systems developed in-house). Anonymous and self-administered questionnaires were distributed to 217 respondents. A total of 185 usable responses were received, resulting in a response rate of $85.3 \%$ which was considered satisfactory for subsequent analysis.

\section{Research Instruments}

Quantitative analysis was chosen to test the research model, as it is good for measuring how many and in what proportion. In addition, with statistically reliable quantitative research it is possible to generalize the results: if the same questions are asked from different people with the same characteristics, the answers should support the outcome of the study.

In order to expedite the data collection process, the Questionnaires were sent out to randomly selected staffs of Azam Company in Dar es salaam, they were accompanied by a cover letter explaining the research objectives and a brief instruction on how to complete the survey. All completed questionnaires were then analysed. The respondents were assured of their confidentiality. The questionnaire contained 25 attributes that were selected out of the 39 items proposed by Bailey and Pearson (1983). The rationale for this was to reduce the complexity of the survey questionnaire. Also, the survey questionnaire did not include any negative questions 
for verification purposes again for the sake of simplification and to reduce the total time taken to provide a complete response. It is foreseeable that including other factors may provide a different insight or improve the internal reliability of the variables studied. However, to perform a vigorous test to qualify the best set of variables would be time consuming and could possibly shorten the duration required for data collection. The questionnaire was comprised of two sections, each containing the selected 25 attributes (see Table 1). The first section asked respondents to evaluate the degree of importance placed upon each attribute. The second section required an evaluation of the actual performance of the same attributes. The respondents were prompted to use a five-point Likert Scale (1. =Very low, 2. = low, 3. = undecided, 4. = high, 5. =very high).

\section{Data Analysis Method}

In this study, descriptive statistics including simple frequencies and mean ratings were computed on the respondents' satisfaction level. The analysis was done with a system designed for statistical analyses (SPSS).

Understanding how well an Information systems is perceived across a range of attributes is not sufficient to guide positioning, if they are not evaluated in terms of importance to the users. Satisfaction results from expectations about important attributes and the perceived performance of those attributes (Myers \& Alpert, 1968). For this reason, Importance-Performance analysis (IPA) was selected as a valid method. The technique considers both the importance of product attributes to the individual as well as the perceived product performance on those attributes.

The IPA matrix, which is presented in Figure 1, represents the two dimensions of attribute importance and performance in four quadrants. The Y-axis plots respondents' importance of the attributes, while the $\mathrm{X}$-axis highlights the perceived product performance on the same attributes. Quadrant 1 features attributes rated most important, but where the product is not perceived to perform strongly. This signals a need for remedial action to improve perceived performance. Quadrant 2 features attributes rated important, and where the product is perceived to perform strongly. It is these attributes that should be reinforced in promotions. Quadrants 3 and 4 feature attributes rated less important, and which should therefore have a lower priority in promotions.

\section{Analysis of Findings}

According to the steps of the IPA approach and empirical questionnaire surveys, the findings indicate that among the twenty five Information System attributes, twelve Information System attributes were in Quadrant 2 (i.e. Keep up the good work), while seven Information System attributes were in quadrant 1 ( that is, Concentrate Here). Another five Information System attributes were in quadrant 3 (that is, Low priority), and one Information System attribute was in quadrant 4 (that is, possible overkill). The analytical results and processes are 
as shown in Table 1. The relative positions of these Information System attributes are as shown in Figure 1. According to the Table 1, the Information System item with the highest mean of importance was 5.12, that is, quality of services provided (code 1); while the lowest mean of importance was 3.30, that is, Degree of training (code 14).

It was found that the respondents were moderately satisfied with the IS performance as indicated by the mean scores (see Table 1). The mean scores in Table 1 indicated that the respondents were the least satisfied with the Degree of Training (the mean score of 2.30) that was provided to them In contrast, the respondents expressed the greatest satisfaction with the following attributes: Overall quality of services provided by the Information System (mean score of 6.01), accessibility (mean score of 5.95), stable network connection service (mean score of 5.93) Integrity of the Systems (mean score of 5.92)and Level of Confidence in the system (mean score of 5.90).

Table 1 also indicates the respondents' perception that almost half (twelve) of attributes surveyed were below their expectations or level of importance (note the negative values for differences in mean scores). The degree of difference, however, varies. From the gap between means, it is easy to see that the IS department needs to work harder to achieve better results on Security of Data, Understanding of the Systems and Documentation. These two items have the highest gap (negative) scores indicating the biggest negative discrepancy between importance and performance. On the other hand, the items with the lowest gap scores suggest that the current performance levels are manageable, even if they are still below end-users' expectations. These include Feeling of Participation (-0.11), Ubiquity in Accessing Applications (-0.21), Security of Data (-0.37), Relationship with the IT) Staff (-0.48), Deployment of changes by IS does not disrupt my work.(-0.54), Information system is relevant to my work (-0.37), control of the information system (-0.62), Job Effect (-0.66) and User friendly (-0.78).

Table 1. IS Attributes, Means, and Gap Scores

\begin{tabular}{|c|c|c|c|c|c|}
\hline Code. & IS Attributes & $\begin{array}{l}\text { Performance } \\
\text { (X) }\end{array}$ & $\begin{array}{l}\text { Importance } \\
\text { (Y) }\end{array}$ & $\begin{array}{l}\text { Mean } \\
\text { Difference } \\
\text { (X-Y= } \\
\text { Gap) }\end{array}$ & $\begin{array}{l}\text { Analytical } \\
\text { Results }\end{array}$ \\
\hline 1. & $\begin{array}{l}\text { There is stable network } \\
\text { connection service }\end{array}$ & 5.93 & 5.12 & 0.81 & $\begin{array}{l}\text { Quadrant } \\
2\end{array}$ \\
\hline 2. & $\begin{array}{l}\text { I have the right set of } \\
\text { applications do my job. }\end{array}$ & 5.85 & 4.96 & 0.89 & $\begin{array}{l}\text { Quadrant } \\
2\end{array}$ \\
\hline 3. & $\begin{array}{l}\text { Applications have accessible } \\
\text { features and functions for } \\
\text { doing my job.(accessibility) }\end{array}$ & 5.95 & 4.78 & 1.17 & $\begin{array}{l}\text { Quadrant } \\
2\end{array}$ \\
\hline 4. & Applications are easy to use. & 5.73 & 4.72 & 1.01 & $\begin{array}{l}\text { Quadrant } \\
2\end{array}$ \\
\hline
\end{tabular}




1.26

Quadrant

5. Applications are available 5.89

when I need them (High

4.63

Availability).

6. Applications respond quickly 5.55

to inputs and commands

(Response/Turnaround

Time).

7. I am satisfied with the overall 6.01 quality of services provided by the Information System.

8. I have a lot of confidence in $\mathbf{5 . 9 0}$ the system

9. Implementation of Latest 5.58 Technology is easy

10 Information systems are 5.86 flexible ( Flexibility of Systems)

11. Top Management are fully 5.03 Involve in Information Systems use

12 Information Systems are well 5.92 integrated (Integrity of the Systems)

13. My work is well enhanced by 5.03 use of Information Systems (Job Effects)

14 The training provided by IT is 2.30 appropriate to my job requirements. (Degree of Training is satisfactory)

15. There is enhanced data 3.70 security when using Information Systems (Security of Data)

16. No Ubiquity in Accessing 3.89 Applications

17. I have easy Understanding of 3.67 the Systems

18. Documentation of the system 3.80 is available

19. I feel in control of the 3.45 information system

20. Information system is 3.85
Quadrant 3

Quadrant 2

Quadrant 2

Quadrant 4

Quadrant 1

Quadrant 1 $-1.07$ Quadrant 1 Quadrant 3

-0.62 Quadrant 1 4.22 $-0.37$ Quadrant 
relevant to my work

21. IT does a good job of keeping

me up to date about what

they're working on.

(Relationship with the IT)

Staff

22. It take short period to develop

an Information system

23. Deployment of changes by IT does not disrupt my work.

24. I have Feeling of Participation when using and information system

25. Information System is User 3.54 friendly
3.19

3.58

3.78

\subsection{4}

1

3.80

$-0.48$

Quadrant

3
3.94

0.75

4.12

3.89

4.32

$-0.54$

$-0.54$

$-0.11$

$-0.78$
Quadrant

3

Quadrant

1

Quadrant

3

Quadrant

Mean scores for both importance and performance data were then plotted as coordinates on the Importance- Performance Scatter graph as depicted in Figure 2. All the means were above 2.3 thus falling in the second quadrant of the IPA graph (refer to Figure 2). To show the resulting positions on the graph more clearly, only the plotted scores are shown (Figure 2). These indicate that both performance and importance of the systems are satisfactory. Therefore, the systems are qualified for further maintenance (cf. Bacon, 2003; Martilla \& James, 1977).

I. Items in Quadrant I (Concentrate Here) includes;

Security of Data (Code 15), No Ubiquity in Accessing Applications (Code 16), Easy Understanding of the Systems (Code 17), Control of the information system (Code 19), Information system is relevant to my work (Code 20), Deployment of changes by IT does not disrupt my work (Code 23) and User friendly (25); meaning that Information Systems users value the importance of these ten items above all other items. However, the way users perceive them as far as satisfaction derived from their performance is concerned is low therefore performance should be improved immediately.

II. Items in Quadrant II (Keep Up the Good Work) includes;

Overall quality of services provided by IS (Code 7), Right set of applications do my job (Code 2), Accessibility (3), Applications are easy to use (code 4), High Availability (Code 5), Response/Turnaround Time (Code 6), stable network connection service (Code 1), Confidence in the system (Code 8), Implementation of Latest Technology is easy (Code 9), Flexibility of Systems (Code 10), Top Management are fully Involve in Information Systems use (Code 11), Integrity of the Systems (Code 12) These thirteen items have a high degree of importance and performance suggested by Information Systems users, as they are the advantages and strength of in cooperating and using Information Systems in a company and key points in future development, and thus, should be maintained. 


\section{Macrothink $\Delta$ Institute ${ }^{\text {tm }}$}

III. Items in Quadrant III (Low Priority) includes;

Degree of Training is satisfactory (Code 14), Availability of Documentation of the system (code 18), Relationship with the IS Staff (Code 21), Shorter period to develop an Information system (code 22), Feeling of Participation (Code 24). For Information Systems users, importance and performance of these items are lower than other items, and Information Systems experts should consider modifying them in the future in order to enhance users' satisfaction.

IV. Items in Quadrant IV (Possible Overkill) include;

Job Effects (Code 13) meaning that Information System users consider the importance of This one items as lower. However, but the satisfaction derived from its performance is high; thus, this item can satisfy Information System users' needs without being overly emphasized.

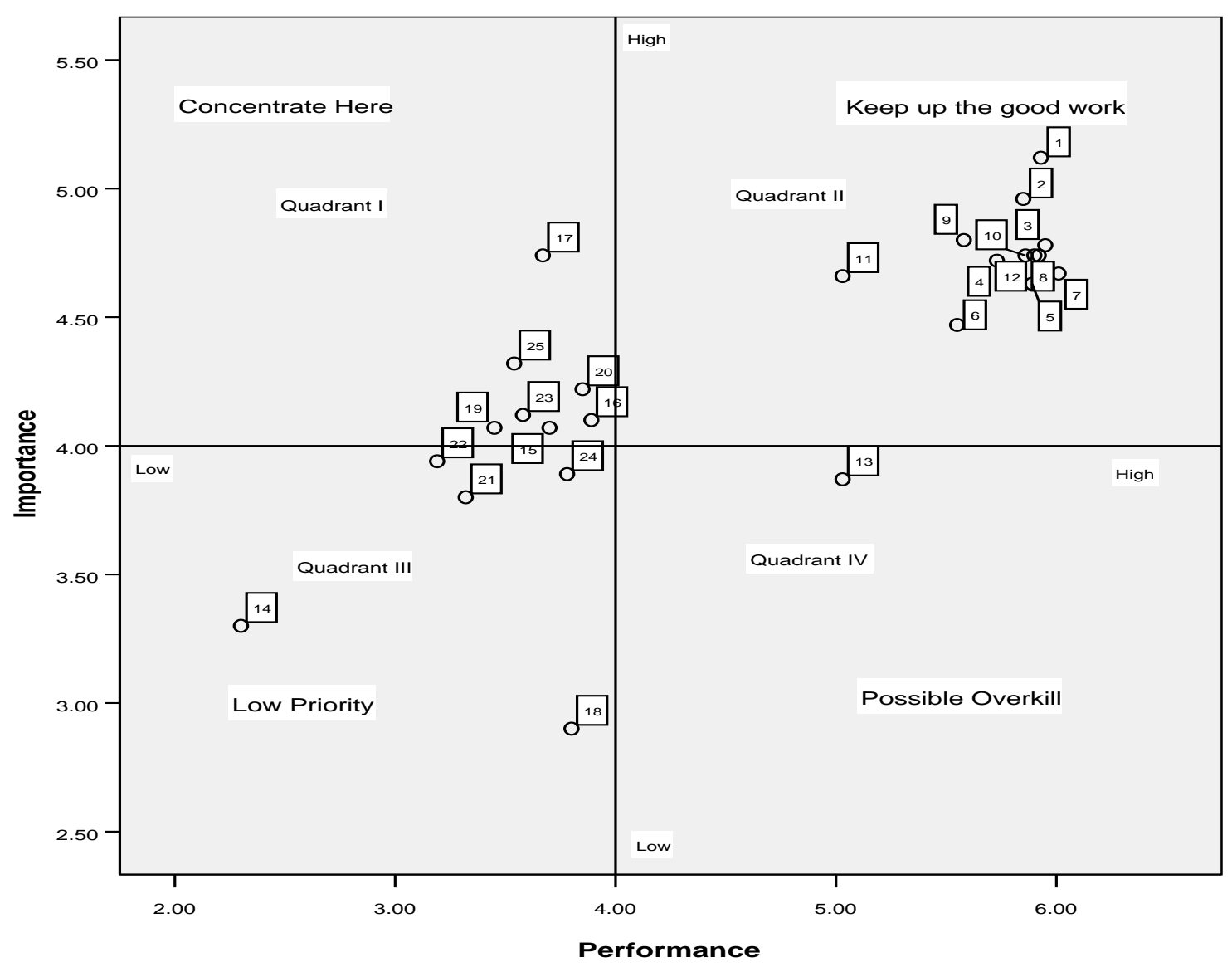


Fig. 2. Point figure of IS attributes.

\section{Conclusion and Discussion}

In this study, the Importance- Performance attributes of information systems were examined among users who were the employees of Azam company in Dar es salaam. The study applied the concept of the IPA approach proposed by Martilla \& James (1977) in order to investigate the perception of the importance of attributes of information systems and whether the performance of information systems met the users' expectations.

Companies today are compelled to analyze the actual value (performance) of their IS. On the practical level, the implication of this is that IS departments should measure the satisfaction level among their end-users as part of evaluating the performance of IS. The same goes for managers in other areas who are responsible for the return on IS investments. End-users' input can reveal insights as to which areas deserve special attention and more resources. Using tested tools such as Bailey and Pearson's (1983) instrument helps ensure a highly consistent, reliable, and valid outcome that, when deployed over time, can help measure the performance of the IS department to ensure its continual alignment between its operational goals and the underlying business objectives. As determined in this study, key IS attributes of IS performance pertain to Service Quality (Relationship with the IS Staff) and System Quality (Response/Turnaround Time and flexibility) are critical in delivering end-user satisfaction (i.e. system performance). On the other hand, data security is deemed to be the most important IS attribute, which echoes today's concern about rampant security threats. These include virus and worm attacks which could lead to data loss, identity theft, hacking by unscrupulous hackers, and unauthorized access to data. As such, an IS department needs to be more proactive in handling these threats and continually demonstrate to the end-users its ability to secure the system and its information repositories. Confidence in the System is also partly related to data security. But even more, this attribute also has to do with the quality of information. The data presented to the user must be reliable, accurate, and timely; otherwise, data will be meaningless and will hinder the end-users from making sound decisions.

The Importance-Performance Map (Table 1) revealed that twelve IS attributes were performing below the end-users' expectations. The three variables with highest gap scores were, Security of Data, Understanding of the Systems and Documentation. The researcher then mapped the mean scores for both data sets onto a scatter plot. For example, to improve end-users' understanding of systems, the IS department could strive to improve its systems' documentation and training. This may include the use of computer-based training, applying multimedia and video to conduct online demonstrations, and organizing "IT open days or IT in-service course" when end-users can approach the IS personnel and inquire about the systems deployed. 


\section{MIN Macrothink}

Based on the gap analysis, the IS department has already fostered good relationships with the end-users, encouraging a high user involvement in the development of new applications. This makes end-users feel that they are more in control and they are assured that the solutions developed are highly relevant to their tasks. The IS department would be wise to maintain their healthy relationship with the end-users, while pursuing the enhancement of the IS attributes identified with the highest gap scores. Managers from the end-users' departments should work together with the IS department to reduce the Importance-Performance gaps. They should play a more active role in the development and implementation of new systems. For example, during the design stage, managers must write and request their specifications based on the functional and procedural requirements, while during the testing stage, managers must test the system thoroughly and extensively.

The limitation of this study is the use of a convenient rather than random sample. Additionally, end-user responses on the perceived importance might have suffered from their desire to rank everything as "very important" in order to suggest a highly concerned outlook on the overall state of the attributes presented. Nevertheless, the study accomplished its purpose of continuing IPA research within the filed of IS, which was only recently imported from the field of marketing.

This application of IPA contributes in several ways. For example, IPA has been used in IS research by Magal and Levenburg (2005) for evaluating e-strategies among small businesses in the United States. The respondents were business owners. In contrast, the present study differs as the respondents are users of systems within a company. Moreover, Skok and colleagues (2001) used IPA to study IS performance of a health club in the United Kingdom by deploying Delone and McLean's (1992 IS success typology. The model incorporates users' satisfaction as a variable to be studied. The present study differs in focusing on the end user satisfaction alone as it considers it a surrogate measure of IS success.

Lastly, it should be noted that most of the previous work on IPA was conducted in more developed countries, such as the United States and the United Kingdom. Little research of this sort has been done in East Africa especially in Tanzania, which belongs in the category of developing countries. 


\section{Reference}

Almanza, B. A., Jaffe, W., \& Lin, L. (1994). Use of the service attribute matrix to measure consumer satisfaction. Hospitality Research Journal, 17(2), 63-75.

Bailey, J.E. \& Pearson, S.W. (1983), Development of a Tool for Measuring and Analyzing Computer User Satisfaction,. Management Science (29:5), pp. 530-545.

Baroudi, J. J., Olson, M. H. \& Ives, B. (1986), An Empirical Study of the Impact of User Involvement on System Usage and Information Satisfaction,. Communications of the ACM (29:3), pp. 232-238.

Chapman, R. G. (1993). Brand performance comparatives. Journal of Products \& Brand Management, 2(1), 42-50.

Cheron, E. J., McTavish, R., \& Perrien, J. (1989). Segmentation of bank commercial markets. International Journal of Bank Marketing, 7(6), 25-30.

Crede, A., \& Mansell, R. (1998). Knowledge societies... in a nutshell: Information technologies for sustainable development. Ottawa, Canada: IDRC

Delone, W. H., \& McLean, E. R. (1992). Information systems success: The quest for the dependent variable. Information Systems Research, 3(1), 60-95. Available at http://business.clemson.edu/ISE/html/information_systems_success_t.html 
Doll, W. J. and Torkzadeh, G. (1988), The Measurement of End-User Computing Satisfaction, MIS Quarterly (12:2), pp. 259-274.

Dolinsky, A. L., \& Caputo, R. K. (1991). Adding a competitive dimension to importanceperformance analysis: An application to traditional health care systems. Health Marketing Quarterly, 8(3/4), 61-79.

Evans, M. R., \& Chon, K. S. (1989). Formulating and evaluating tourism policy using importance- performance analysis. Hospitality Education and Research Journal, 13, 203-213.

Ford, J. B., Joseph, M., \& Joseph, B. (1999). IPA as a strategic tool for service marketers: The case of service quality perceptions of business students in New Zealand and the USA. Journal of Services Marketing,13(2), 171 - 186.

Hawes, J. M., Kiser, G. E.,\& Rao, C. P. (1982). Analysing the market for planned retirement communities in the Southwest. Baylor Business Studies, 13, 39-46.

Hawes, J. M., \& Rao, C. P. (1985). Using importance-performance analysis to develop health care marketing strategies. Journal of Health Care Marketing, 5(4), 19-25.

Hemmasi, M., Strong, K. C., \& Taylor, S. A. (1994). Measuring service quality for strategies planning and analysis in service firms. Journal of Applied Business Research, 10(4), 24-34.

Hsu, C. H. C., Byun, S., \& Yang, I. S. (1997). Attitudes of Korean college students towards quick- service, family-style, and fine dining restaurants. Journal of Restaurant \& Foodservice Marketing, 2(4), 65-85.

Ives, B., Olson, M., \& Baroudi, J. J. (1983). The measurement of user information satisfaction. Communication of the ACM, 26(10), 785-793. Available at http://business.clemson.edu/ISE/html/the_measurement_of_user_inform.html

Joseph, M., Allbrigth, D., Stone, G., Sekhon, Y., \& Tinson, J. (2005). IPA of UK and US Bank: Customer perceptions of service delivery technologies. International Journal of Financial Services Management, 1(1), 66 - 88

Keyt, J. C., Yavas, U., \& Riecken, G. (1994). Importance-performance analysis: A case study in restaurant positioning. International Journal of Retail and Distribution Management, 22(5), 35-40.

Lewis, R. C. (1985). Getting the most from marketing research [Part V]. Predicting hotel choice: The factors underlying perception. The Cornell Hotel and Restaurant Administration Quarterly, 26(3), 82-96. 
Magal, S., \& Levenburg, N. M. (2005). Using IPA to evaluate e-business strategies among small businesses. Proceedings of the 38th Hawaii International Conference on System Sciences; Jan 3-6, 2005; Hilton Waikoloa Village Island of Hawaii, USA

Martila, J. A., \& James, J. C. (1977). Importance-performance analysis. Journal of Marketing, 2(1), 77-79.

Ombati O. T., Maguta O. P., Nyamwange O. S \& Nyaoga B. R. (2010), Technology And Service Quality In The Banking Industry Importance And Performance Of Various Factors Considered In The Electronic Banking Services, African Journal of Business \& Management (AJBUMA), April 12, 2010

Parasuraman, A., Zeithaml, V. A., \& Berry, L. L. (1988). SERVQUAL: A multiple-item scale for measuring consumer perceptions of service quality. Journal of Retailing, 64(1), 12-37.

Sethna, B. N. (1982). Extensions and testing of Importance-performance analysis. Business Economics, 28-31.

Shaw, N. C., Delone, W. H., \& Niederman, F. (2002). Sources of dissatisfaction in end-user support: An empirical study. Data Base for Advances in Information Systems, 33(2), 41-56.

Skok, W., Kophamel, A., \& Richardson, I. (2001). Diagnosing information systems success: Importance-performance maps in the health club industry. Information \& Management, 38, 409-419.

Slack, N. (1994). The importance-performance matrix as a determinant of improvement priority. International Journal of Operations \& Production Management, 14(5), 59-76.

Thioune, R.M.C. (2003). Information and communication technologies for development in Africa: Opportunities and challenges for community development. Volume 1. Ottawa: IDRC. Available: http://www.idrc.ca

Wade, J. D. \& Eagle J. F. P. (2003), Analysis and Market Segmentation for Tourism Management in Parks and Protected Areas: An Application to Tanzania's National Parks, Journal of Ecotourism, vol. 2, No. 3, 2003

Yeo, A. Y. C. (2003). Examining a Singapore bank's competitive superiority using importance- performance analysis. Journal of American Academy of Business, 3(1/2), 155-161. 
